\title{
20 YEARS OF ANNALS OF KEMU (1995 - 2015)
}

The Annals of KEMU was first published in 1995, and Prof. Abdul Majeed Ch. was the first editor. I was appointed as editor on $15^{\text {th }}$ May 2007, the responsibility which I will be completing on my retirement on $9^{\text {th }}$ December, 2015. A brief report of Annals of KEMU from 15-05-2007 to 09-12-2015 is stated below for kind information of the authors, reviewers and readers of the Annals.

The title of Annals of KEMC was changed to Annals of KEMU, new editorial board was constituted and editorial policy was made and approved on $14^{\text {th }}$ June 2007. According to editorial policy 2007, the editorial process was divided into six (6) steps; 1Manuscript Submission, 2-Plagiarism Check with "Turnitun", 3-review of manuscript by two reviewers, 4-acceptance/rewriting/rejection, 5-publication and 6circulation.

As a result of high quality, the Annals was recognized by PMDC in 2009. The HEC recognized Annals first in category " $\mathrm{Z}$ " and later on raised the category to "Y" and in July 2015 to highest category "X".

Annals of KEMU has been indexed with; 1-Pak MediNet (1996), 2-EMRO Indexus of WHO (1997), 3-Directory of Open Access Journals-DOAJ (2007), 4ICJME Database(2010), 5-PKP Harvester Database, 6Open J Gate Database (2010), 7-Google Scholar.

From June 2007 to November 2015, thirty five (35) issues of Annals of KEMU were published. Five hundred and sixty (560) manuscript were received, four hundred and thirty eight (38) manuscripts were accepted and published, forty three (43) were rejected, and four (04) manuscripts were withdrawn by authors. Until December 2015, seventy five (75) manuscripts are in editorial review process.

Total income of the Annals from June 2007 to December 2015 was Rs. 12,52,280/- (Grant from HEC Rs. 6,12,280, collection from authors at rate of Rs. 1,000 for processing each manuscript Rs. 5,60,000 and from advertisements Rs. 80,000. During this period the expenditures of Annals have been Rs. 12,80,215 (publication cost Rs. 11,36,215 and correspondence and circulation Rs $1,44,000$ ). In this way the cost to KEMU treasury has been Rs. 27,935/-.

The credit for the achievements of; maintaining good quality (plagiarism below 19\% and approval by two reviewers of same specialty), achieving PMDC recognition and highest HEC rank, having Annals indexed with 7 databases and just cost of Rs. 27, 935 to KEMU treasury for publishing of 35 Issues goes to our able editorial board, authors, reviewers and the staff. I take this opportunity to thank all of them, especially the editorial secretaries, Mr. Asim Saeed and Mr. Muhammad Afzal (Assistant Annals of KEMU), who have worked very hard.

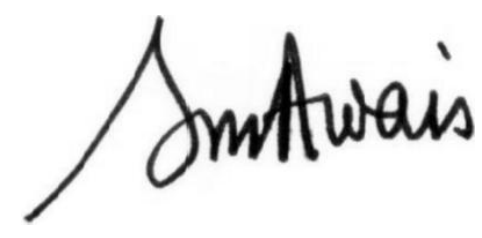

Prof. Dr. Syed Mohammad Awais (Sitara-e-Imtiaz)

Editor Annals of KEMU 